\title{
CPAP Devices for Emergency Prehospital Use: A Bench Study
}

\author{
Claudia Brusasco MD, Francesco Corradi MD PhD, Alessandra De Ferrari MD, Lorenzo Ball MD, \\ Robert M Kacmarek PhD RRT FAARC, and Paolo Pelosi MD
}

\begin{abstract}
BACKGROUND: CPAP is frequently used in prehospital and emergency settings. An air-flow output minimum of $60 \mathrm{~L} / \mathrm{min}$ and a constant positive pressure are 2 important features for a successful CPAP device. Unlike hospital CPAP devices, which require electricity, CPAP devices for ambulance use need only an oxygen source to function. The aim of the study was to evaluate and compare on a bench model the performance of 3 orofacial mask devices (Ventumask, EasyVent, and Boussignac CPAP system) and 2 helmets (Ventukit and EVE Coulisse) used to apply CPAP in the prehospital setting. METHODS: A static test evaluated air-flow output, positive pressure applied, and $\mathrm{F}_{\mathrm{IO}_{2}}$ delivered by each device. A dynamic test assessed airway pressure stability during simulated ventilation. Efficiency of devices was compared based on oxygen flow needed to generate a minimum air flow of $60 \mathrm{~L} / \mathrm{min}$ at each CPAP setting. RESULTS: The EasyVent and EVE Coulisse devices delivered significantly higher mean air-flow outputs compared with the Ventumask and Ventukit under all CPAP conditions tested. The Boussignac CPAP system never reached an air-flow output of $60 \mathrm{~L} / \mathrm{min}$. The EasyVent had significantly lower pressure excursion than the Ventumask at all CPAP levels, and the EVE Coulisse had lower pressure excursion than the Ventukit at 5, 15, and $20 \mathrm{~cm} \mathrm{H}_{2} \mathrm{O}$, whereas at $10 \mathrm{~cm} \mathrm{H}_{2} \mathrm{O}$, no significant difference was observed between the 2 devices. Estimated oxygen consumption was lower for the EasyVent and EVE Coulisse compared with the Ventumask and Ventukit. CONCLUSIONS: Air-flow output, pressure applied, $\mathrm{F}_{\mathrm{IO}_{2}}$ delivered, device oxygen consumption, and ability to maintain air flow at $60 \mathrm{~L} / \mathrm{min}$ differed significantly among the CPAP devices tested. Only the EasyVent and EVE Coulisse achieved the required minimum level of air-flow output needed to ensure an effective therapy under all CPAP conditions. Key words: noninvasive CPAP; emergency department; ambulance; cardiogenic pulmonary edema; helmet CPAP; Boussignac; acute respiratory failure. [Respir Care 2015;60(12):1777-1785. (C) 2015 Daedalus Enterprises]
\end{abstract}

\section{Introduction}

Noninvasive ventilation (NIV) reduces the need for endotracheal intubation, the occurrence of nosocomial infec-

Drs Brusasco, De Ferrari, Ball, and Pelosi are affiliated with the Dipartimento di Scienze Chirurgiche e Diagnostiche Integrate, Sezione Anestesia e Rianimazione, Università degli Studi di Genova, Genova, Italy. Drs De Ferrari, Ball, and Pelosi are also affiliated with the Istituto di Ricovero e Cura a Carattere Scientifico (IRCCS) Azienda Ospedaliera Universitaria San Martino-Istituto Scientifico Tumori, Genova, Italy. Dr Corradi is affiliated with the SC Anestesia e Rianimazione, EO Ospedali Galliera, Genova, Italy. Dr Kacmarek is affiliated with the Department of Anesthesiology and Critical Care and the Department of Respiratory Care, Massachusetts General Hospital, Boston, Massachusetts.

Dr Kacmarek has disclosed relationships with Covidien and Venner Medical. The other authors has disclosed no conflicts of interest. tions, and both morbidity and mortality associated with respiratory failure. ${ }^{1-5}$ The benefits of NIV are greater if started early, thus constituting the rationale for the increasing use of NIV in prehospital and emergency department settings. ${ }^{6-8}$ Because of its ease of use and the small size of commercially available devices, CPAP is the most commonly used NIV technique in these settings. ${ }^{5,9}$ The benefits of CPAP have been extensively described in the treatment of acute cardiogenic pulmonary edema ${ }^{10-12}$ and acute

\footnotetext{
Correspondence: Claudia Brusasco MD, Dipartimento di Scienze Chirurgiche e Diagnostiche Integrate, Sezione Anestesia e Rianimazione, Università degli Studi di Genova, Largo Rosanna Benzi 8, 16132 Genova, Italy. E-mail: claudia.brusasco@gmail.com.
}

DOI: $10.4187 /$ respcare.04134 
respiratory failure ${ }^{13-15}$ and include opening collapsed alveoli, preserving patency of already open-lung units, improving gas exchange, reducing patient's work of breathing, ${ }^{16}$ and increasing cardiac performance by a reduction in venous return and left-ventricular afterload. ${ }^{17-19}$ CPAP can be delivered with masks or helmets.

For successful CPAP treatment, CPAP devices must deliver sufficiently high air flow to maintain airway pressure throughout the breathing cycle. Because conditions such as tachypnea, high minute ventilation, or large tidal volumes can increase inspiratory flows, air flow delivered by CPAP devices should always be higher than the patient's peak inspiratory flow to ensure positive airway pressure during the entire breathing cycle. A minimum of 60 $\mathrm{L} / \mathrm{min}$ is generally considered sufficient to guarantee a constant CPAP level under most degrees of patient inspiratory demand, ${ }^{20}$ although higher flows might be required in severe respiratory distress at high breathing frequency, large tidal volumes, and high minute ventilation. ${ }^{20,21}$ Delivered $\mathrm{F}_{\mathrm{IO}_{2}}$ is dependent upon the amount of air entrained during the operation of the device and the patient's inspiratory demand. If the device entrains a large volume of room air, the maximum $\mathrm{F}_{\mathrm{IO}_{2}}$ will be limited. In addition, the more that the patient's inspiratory demand exceeds the total air-flow output of the device, the lower the $\mathrm{F}_{\mathrm{IO}_{2}}$ will be because additional room air must be entrained to meet the patient's demand for inspiratory flow.

The aim of this study was to evaluate and compare the intrinsic capabilities of 5 commercially available CPAP devices in prehospital and emergency settings. The performance of each device was evaluated in terms of effectiveness (air-flow output, pressure, and $\mathrm{F}_{\mathrm{IO}_{2}}$ ) and efficiency (oxygen consumption by the device).

\section{Methods}

\section{Devices}

Five commercially available devices for delivery of noninvasive CPAP in prehospital settings were studied (Fig. 1): 3 orofacial mask devices (Ventumask [StarMed, Mirandola, Italy], EasyVent [Dimar, Mirandola, Italy], and Boussignac CPAP system [Vygon, Écouen, France]) and 2 helmet-type devices (Ventukit [StarMed] and EVE Coulisse [Dimar]). All of these devices require only an oxygen source to generate CPAP, thus making them useful on ambulances.

The Ventumask, EasyVent, Ventukit, and EVE Coulisse devices use the Venturi effect to entrain room air and generate a high gas output flow and an adjustable mechanical CPAP valve to set the desired positive pressure. A supplementary oxygen source located downstream from the air-entrainment valve can be connected to increase $\mathrm{F}_{\mathrm{IO}_{2}}$. Tables provided by the manufacturers indicate, for

\section{QUICK LOOK}

\section{Current knowledge}

CPAP is frequently used in prehospital and emergency settings. A minimum flow output of $60 \mathrm{~L} / \mathrm{min}$ and a constant positive pressure are 2 important features of a successful CPAP device. CPAP devices for ambulances typically need only an oxygen source to function. Inspired oxygen can be altered by air entrainment, which also increases total flow. Prehospital use of CPAP for cardiogenic pulmonary edema is associated with improved clinical outcomes.

\section{What this paper contributes to our knowledge}

In a bench study of 5 CPAP devices, there were considerable differences in performance among the devices tested. The EasyVent and EVE Coulisse achieved the best overall performance in terms of effectiveness and efficiency; the Ventumask and Ventukit presented more limited air-flow outputs at lower positive pressures; and the Boussignac CPAP system delivered low total airflow outputs, low positive pressures, and high nonadjustable $\mathrm{F}_{\mathrm{IO}_{2}}$. Clinicians and prehospital caregivers should be aware of specific device performance characteristics to optimize effective application of CPAP in prehospital and emergency settings.

each level of CPAP, the oxygen flows needed to provide a specific total air flow and $\mathrm{F}_{\mathrm{IO}_{2}}$ with a maximum use of 15 L/min oxygen.

The Boussignac CPAP system uses the virtual Boussignac valve, consisting of a small cylinder with 4 microchannels: when receiving oxygen flow from a source, turbulence is generated inside the cylinder itself, resulting in a positive pressure. The performance of the Boussignac CPAP system depends only on the delivered oxygen flow: $\mathrm{F}_{\mathrm{IO}_{2}}$ and positive pressure cannot be set by the operator because both are a result of the oxygen flow setting required to power the device and the amount of air the patient inhales above that delivered by the device. This device does not incorporate an air-entrainment Venturi system.

The Ventukit and EVE Coulisse are 2 transparent, latexfree, polyvinylchloride hoods joined by a metal ring to soft polyvinylchloride collars to form helmets. These devices have an internal gas volume of $17 \mathrm{~L}$. Both helmets include an air-entrainment system utilizing the Venturi effect and an adjustable CPAP valve. The Ventukit helmet has a plug to reduce the noise generated by the device at the exit point of the flow generated by the air-entrainment Venturi system exerting $6 \mathrm{~cm} \mathrm{H}_{2} \mathrm{O}$ per $50 \mathrm{~L} / \mathrm{min}$ resistance to gas flow. 

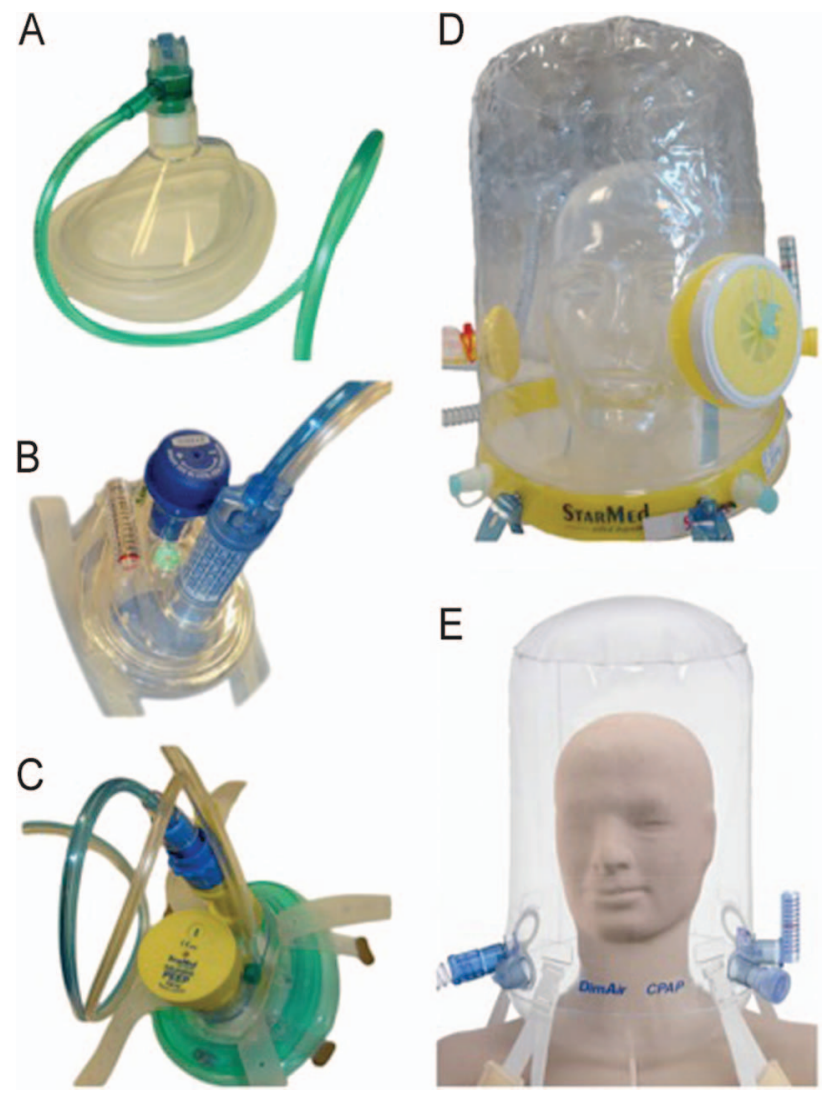

Fig. 1. The 5 tested devices. A: Boussignac CPAP system; B: EasyVent; C: Ventumask; D: Ventukit; E: EVE Coulisse.

Comparisons were performed between masks and between helmets because the devices from the same manufacturer (Ventumask/Ventukit and EasyVent/EVE Coulisse) use the same air-entrainment system and the difference between devices is the interfaces (mask or helmets). Moreover, the choice to use a mask or a helmet is strictly clinical, based on the patient's adherence or expected duration of needed assistance.

\section{Experimental Setting}

Figure 2 shows the in vitro circuit used to evaluate the performance of each device in terms of flow, generated pressure, and delivered $\mathrm{F}_{\mathrm{IO}_{2}}$. A flow meter (ICU-Lab, KleisTEK, Bari, Italy) measuring air flow generated by the CPAP device was positioned downstream from each CPAP device's air-entrainment valve, as well as a rapid-response oxygen analyzer $\left(\mathrm{MaxO}_{2}{ }^{+} \mathrm{AE}\right.$, Maxtec, Salt Lake City, Utah) and a manometer.

The Ventumask, EasyVent, Ventukit, and EVE Coulisse devices were evaluated without CPAP and at 4 levels of CPAP $\left(5,10,15\right.$, and $\left.20 \mathrm{~cm} \mathrm{H}_{2} \mathrm{O}\right)$ set with each device's adjustable valve. For each CPAP valve level, the devices were tested at oxygen source flows of $5-15 \mathrm{~L} / \mathrm{min}$ in 1
$\mathrm{L} / \mathrm{min}$ increments, and generated pressure, air flow, and $\mathrm{F}_{\mathrm{IO}_{2}}$ were measured. The Boussignac CPAP system was evaluated for delivered air flow, $\mathrm{F}_{\mathrm{IO}_{2}}$, and pressure starting at $5 \mathrm{~L} / \mathrm{min}$ oxygen up to $30 \mathrm{~L} / \mathrm{min}$, as recommended by the manufacturer, in $1 \mathrm{~L} / \mathrm{min}$ increments from 5 to $15 \mathrm{~L} / \mathrm{min}$ and then in $5 \mathrm{~L} / \mathrm{min}$ steps to $30 \mathrm{~L} / \mathrm{min}$.

Each device was evaluated during simulated spontaneous breathing using a lung model. Airway pressure stability throughout the breathing cycle, estimated by calculating the mean of the pressure excursion inside the device chamber (maximum pressure-minimum pressure $=$ excursion pressure), was used as an indirect index of work of breathing. As shown in Figure 2, a pneumatic lung simulator (Dimar) generating a mildly tachypneic sinusoidal flow pattern (tidal volume $500 \mathrm{~mL}$, inspiratory time $0.8 \mathrm{~s}$, expiratory time $1.6 \mathrm{~s}$, breathing frequency 25 breaths/min) was directly connected to each device. A pneumotachograph and pressure transducer (ICULab) were positioned between devices and the pneumatic lung simulator, and each device was tested during $60 \mathrm{~s}$ of uninterrupted simulated breathing. Air-entrainment devices were evaluated by delivering increasing levels of oxygen flow from 5 to $15 \mathrm{~L} / \mathrm{min}$ in $1 \mathrm{~L} / \mathrm{min}$ increments and then from 15 to $30 \mathrm{~L} / \mathrm{min}$ in $5 \mathrm{~L} / \mathrm{min}$ increments and at 4 different CPAP levels $\left(5,10,15\right.$, and $\left.20 \mathrm{~cm} \mathrm{H}_{2} \mathrm{O}\right)$, set with each device's adjustable CPAP valve. The Boussignac CPAP system was tested by delivering an increasing flow of oxygen from 5 to $30 \mathrm{~L} / \mathrm{min}$. For all devices, pressure excursion was calculated as mean of the pressure excursion over the 25 ventilatory cycles occurring during the recording time.

In addition, device oxygen consumption or rather oxygen inflow requirement was calculated from an oxygen tank (volume of $7 \mathrm{~L}$ ) fully charged at 200 bar for a total $1,400 \mathrm{~L}$ of oxygen. The oxygen flow needed to generate a minimum air-flow output of $60 \mathrm{~L} / \mathrm{min}$ was used to estimate efficiency in total minutes of run time. All experiments were carried out by the same researcher $(\mathrm{CB})$.

\section{Statistical Analysis}

Data are expressed as mean \pm SD. All statistical analyses were performed using SPSS 21 (IBM, Armonk, New York), and significance was considered to be $P<.05$. All data were analyzed by averaging measurements on 3 different devices of each evaluated model.

\section{Gas Output Flow Generation Performances}

The total gas output flow obtainable with the different devices was compared by 2-way analysis of variance, with input flow and device as factors. The relationship between oxygen input flow and generated air-flow outputs of each device was tested by linear regression analysis. 


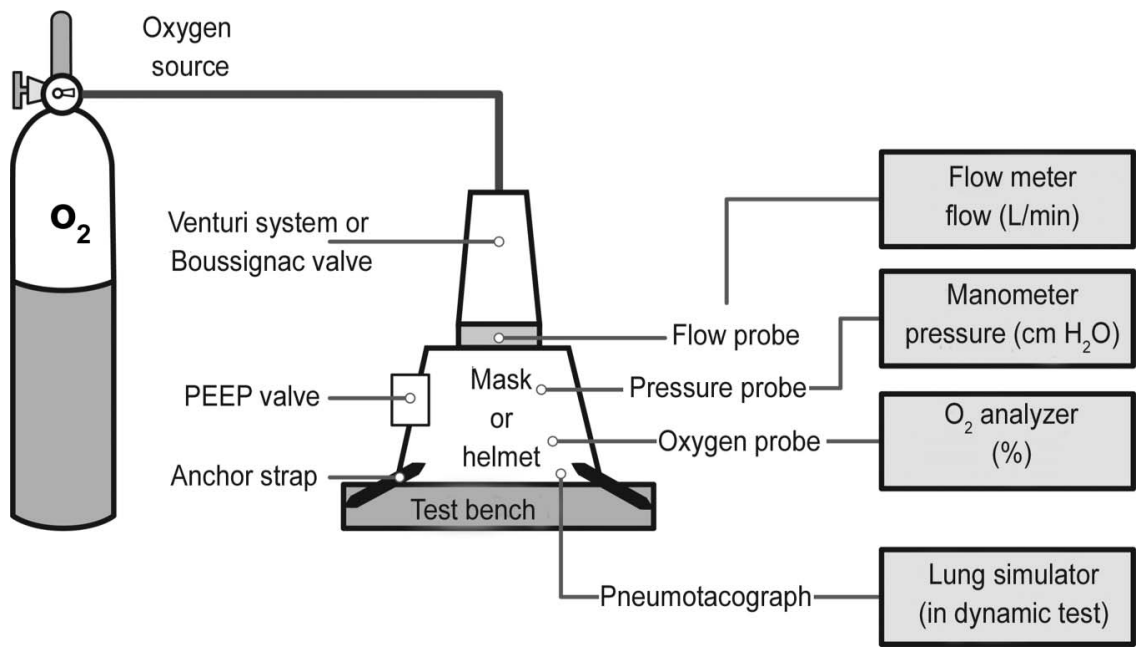

Fig. 2. Illustration of the in vitro circuit used to evaluate the performance of each device in terms of flow, generated pressure, and delivered $\mathrm{F}_{1 \mathrm{O}_{2}}$.

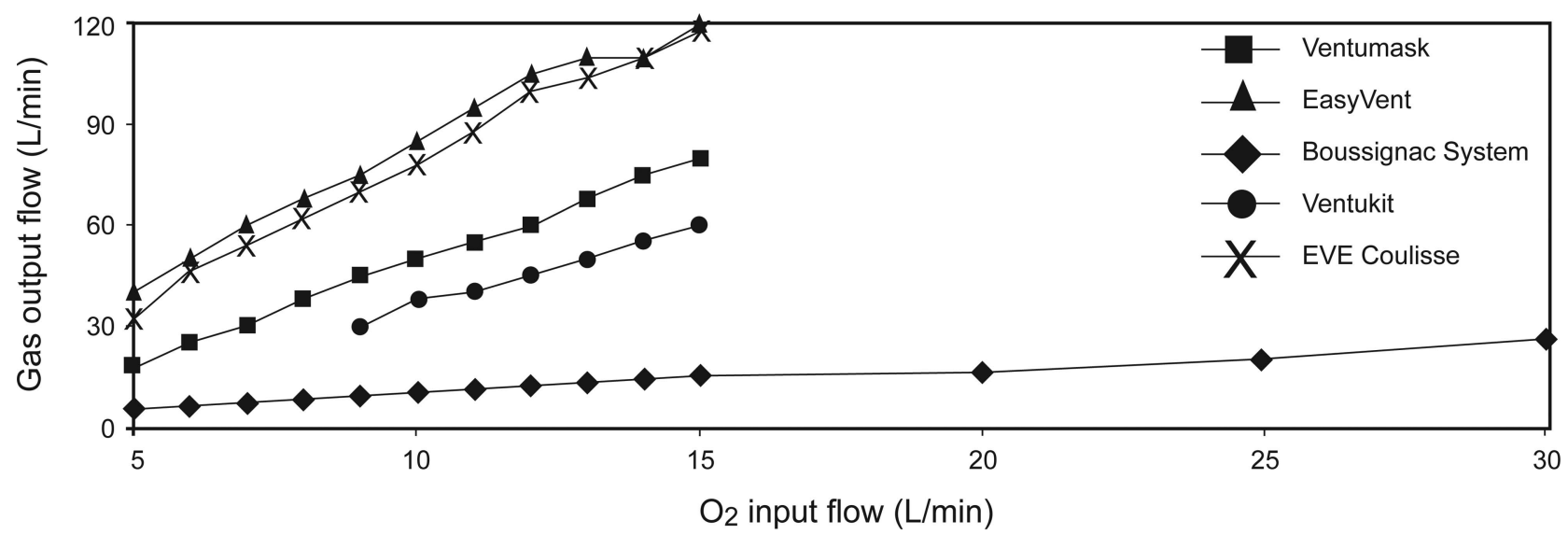

Fig. 3. Air-flow outputs generated by each device at different oxygen flows from 5 to $15 \mathrm{~L} / \mathrm{min}$ in $1 \mathrm{~L} / \mathrm{min}$ increments without any CPAP valve.

\section{Static Test}

Masks and helmets were analyzed separately. The generated flows and $\mathrm{F}_{\mathrm{IO}_{2}}$ of devices, at a fixed oxygen input flow of $15 \mathrm{~L} / \mathrm{min}$, were compared by 2-way analysis of variance, with CPAP level and device as factors. Differences between devices at a given CPAP level were tested post hoc, and $P$ values of multiple comparisons were corrected using the Bonferroni correction.

\section{Dynamic Test}

Masks and helmets were analyzed separately. Normality of distributions was assessed by the D'Agostino-Pearson omnibus test, and correlations were assessed by Pearson R or Spearman's rho, accordingly. Pressure excursions of masks and helmets were compared by 2-way analysis of variance, with CPAP level and device as factors. Differ- ences between devices at a given CPAP level were tested post hoc, and $P$ values of multiple comparisons were corrected using the Bonferroni correction.

\section{Results}

\section{Gas Output Flow Generation Performances}

The gas output flow of each device without a CPAP valve was linearly related to the oxygen input flow (Fig. 3 ), and the results of linear regression are reported in Table 1. The EasyVent $(83 \pm 27 \mathrm{~L} / \mathrm{min})$ and EVE Coulisse (78 $\pm 28 \mathrm{~L} / \mathrm{min}$ ) produced a greater air-flow output than the Ventumask ( $49 \pm 20 \mathrm{~L} / \mathrm{min})$, Boussignac CPAP system $(10 \pm 4 \mathrm{~L} / \mathrm{min})$, and Ventukit $(45 \pm 10 \mathrm{~L} / \mathrm{min})$ at all oxygen input flows $(P<.001$ for comparisons between all pairs of devices, except EasyVent vs EVE Coulisse at an input flow of $14 \mathrm{~L} / \mathrm{min}, P>.99$ ). 
Table 1. Output Flow Generation Performance of Each Tested Device

\begin{tabular}{lccr}
\hline \hline \multicolumn{1}{c}{ Device } & Slope $(95 \% \mathrm{CI})$ & Intercept $(95 \% \mathrm{CI})$ & \multicolumn{1}{c}{$\mathrm{r}^{2}$} \\
\hline Boussignac system & $0.7-0.9$ & 0.8 to 3.1 & 0.97 \\
Ventumask & $5.9-6.4$ & -14.5 to -9.8 & $>0.99$ \\
EasyVent & $4.8-11.0$ & 7.3 to 8.8 & 0.98 \\
Ventukit & $4.2-5.3$ & -18.7 to -5.3 & 0.99 \\
EVE Coulisse & $7.9-9.0$ & -11.8 to -0.5 & $>0.99$ \\
& & & \\
Results of linear regression of output flow versus input flow are reported. &
\end{tabular}

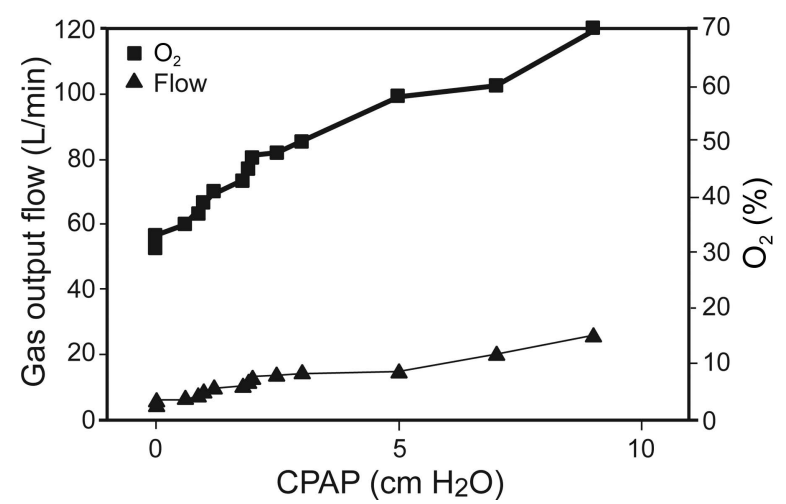

Fig. 4. Performances of the CPAP Boussignac system. The $X$ axis represents CPAP values. The left $Y$ axis represents air-flow outputs, and the right $Y$ axis represents $F_{1 O_{2}}$ generated at different oxygen flows from 5 to $30 \mathrm{~L} / \mathrm{min}$. Point labels are input flows (L/min). With the Boussignac CPAP system, output flows were slightly lower than input flows, possibly due to oxygen leakage through the virtual valve.

\section{Static Test}

Masks. Considering the architectural differences between the Boussignac CPAP system and the other 4 devices (in particular, the inability to preset a positive pressure and $\mathrm{F}_{\mathrm{IO}_{2}}$ ), an initial separate characterization was performed (Fig. 4). The maximum positive pressure achieved with the Boussignac CPAP system was $9 \mathrm{~cm} \mathrm{H}_{2} \mathrm{O}$ at an oxygen input flow of $30 \mathrm{~L} / \mathrm{min}$; therefore, no direct comparison with other mask devices could be performed at CPAP levels of 10,15 , and $20 \mathrm{~cm} \mathrm{H}_{2} \mathrm{O}$.

At a CPAP of $5 \mathrm{~cm} \mathrm{H}_{2} \mathrm{O}$, the EasyVent generated a higher output flow than the Ventumask and Boussignac (120, 75, and $15 \mathrm{~L} / \mathrm{min}$, respectively; $P<.001$ for all pairwise comparisons), with a lower $\mathrm{F}_{\mathrm{IO}_{2}}(31,37$, and $58 \%$, $P<.001$ for all comparisons). At a CPAP of $10 \mathrm{~cm} \mathrm{H}_{2} \mathrm{O}$, the EasyVent generated a higher output flow than the Ventumask (118 vs $70 \mathrm{~L} / \mathrm{min}, P<.001)$, with a lower $\mathrm{F}_{\mathrm{IO}_{2}}$ (30\% vs $40 \%, P<.001$ ). At a CPAP of $15 \mathrm{~cm} \mathrm{H}_{2} \mathrm{O}$, the EasyVent generated a higher output flow than Ventumask (100 vs $72 \mathrm{~L} / \mathrm{min}, P<.001)$, with a lower $\mathrm{F}_{\mathrm{IO}_{2}}(33 \%$ vs $42 \%, P<.001)$. At a CPAP of $20 \mathrm{~cm} \mathrm{H}_{2} \mathrm{O}$, the EasyVent generated a higher output flow than the Ventumask (90 vs $40 \mathrm{~L} / \mathrm{min}, P<.001)$, with a lower $\mathrm{F}_{\mathrm{IO}_{2}}(35 \%$ vs $55 \%, P<$ $.001)$.

Helmets. At a CPAP of $5 \mathrm{~cm} \mathrm{H}_{2} \mathrm{O}$, the EVE Coulisse generated a higher output flow than the Ventukit (120 vs $60 \mathrm{~L} / \mathrm{min}, P<.001)$, with a lower $\mathrm{F}_{\mathrm{IO}_{2}}(31 \%$ vs $41 \%, P<$ .001). At a CPAP of $10 \mathrm{~cm} \mathrm{H}_{2} \mathrm{O}$, the EVE Coulisse generated a higher output flow than the Ventukit (112 vs 46 L/min, $P<.001)$, with a lower $\mathrm{F}_{\mathrm{IO}_{2}}(30 \%$ vs $47 \%, P<$ $.001)$. At a CPAP of $15 \mathrm{~cm} \mathrm{H}_{2} \mathrm{O}$, the EVE Coulisse generated a higher output flow than the Ventukit (95 vs 35 $\mathrm{L} / \mathrm{min}, P<.001)$, with a lower $\mathrm{F}_{\mathrm{IO}_{2}}(32 \%$ vs $54 \%, P<$ $.001)$. At a CPAP of $20 \mathrm{~cm} \mathrm{H}_{2} \mathrm{O}$, the EVE Coulisse generated a higher output flow than the Ventukit ( 80 vs 20 $\mathrm{L} / \mathrm{min}, P<.001)$, with a lower $\mathrm{F}_{\mathrm{IO}_{2}}(34 \%$ vs $80 \%, P<$ $.001)$.

A comparison of the overall efficiency of all devices with the static test is illustrated in Figures 4 and 5. All CPAP devices showed a reduction of air-flow output and an increase in $\mathrm{F}_{\mathrm{IO}_{2}}$ as the CPAP level was increased.

\section{Dynamic Test}

Because the Boussignac CPAP system never reached a minimum air-flow output of $60 \mathrm{~L} / \mathrm{min}$, it was considered not to be comparable with the other devices and was not included in the dynamic bench test. Normality assumption for pressure excursion distribution was rejected for both masks and helmets, with $P<.001$. The dynamic bench test showed a significant negative correlation between the gas flow generated by the CPAP devices and the pressure excursion inside the device for both masks (rho $=-0.86$, $P=.01$ ) and helmets (rho $=-0.79, P=.03$ ). For both air-entrainment masks and helmets, a steep decrease in pressure excursion was observed when the delivered flow reached the threshold of $60 \mathrm{~L} / \mathrm{min}$ (Fig. 6). Absolute values of pressure excursion were lower in helmets due to their high internal volume.

The EasyVent had significantly lower pressure excursion than the Ventumask at all CPAP levels $(P<.001)$, and the EVE Coulisse had lower pressure excursion than the Ventukit at $5 \mathrm{~cm} \mathrm{H}_{2} \mathrm{O}(P<.001), 15 \mathrm{~cm} \mathrm{H}_{2} \mathrm{O}(P=$ $.02)$, and $20 \mathrm{~cm} \mathrm{H}_{2} \mathrm{O}(P<.001)$, whereas at $10 \mathrm{~cm} \mathrm{H}_{2} \mathrm{O}$, no significant difference was observed between the 2 devices $(P>.99)$. The results of the dynamic test are illustrated in Figure 7. The efficiency of devices in terms of oxygen consumption needed to achieve the output flow threshold of $60 \mathrm{~L} / \mathrm{min}$ at a given CPAP level are reported in Table 2.

\section{Discussion}

The major findings of this study are: (1) different devices for noninvasive CPAP varied significantly in their 

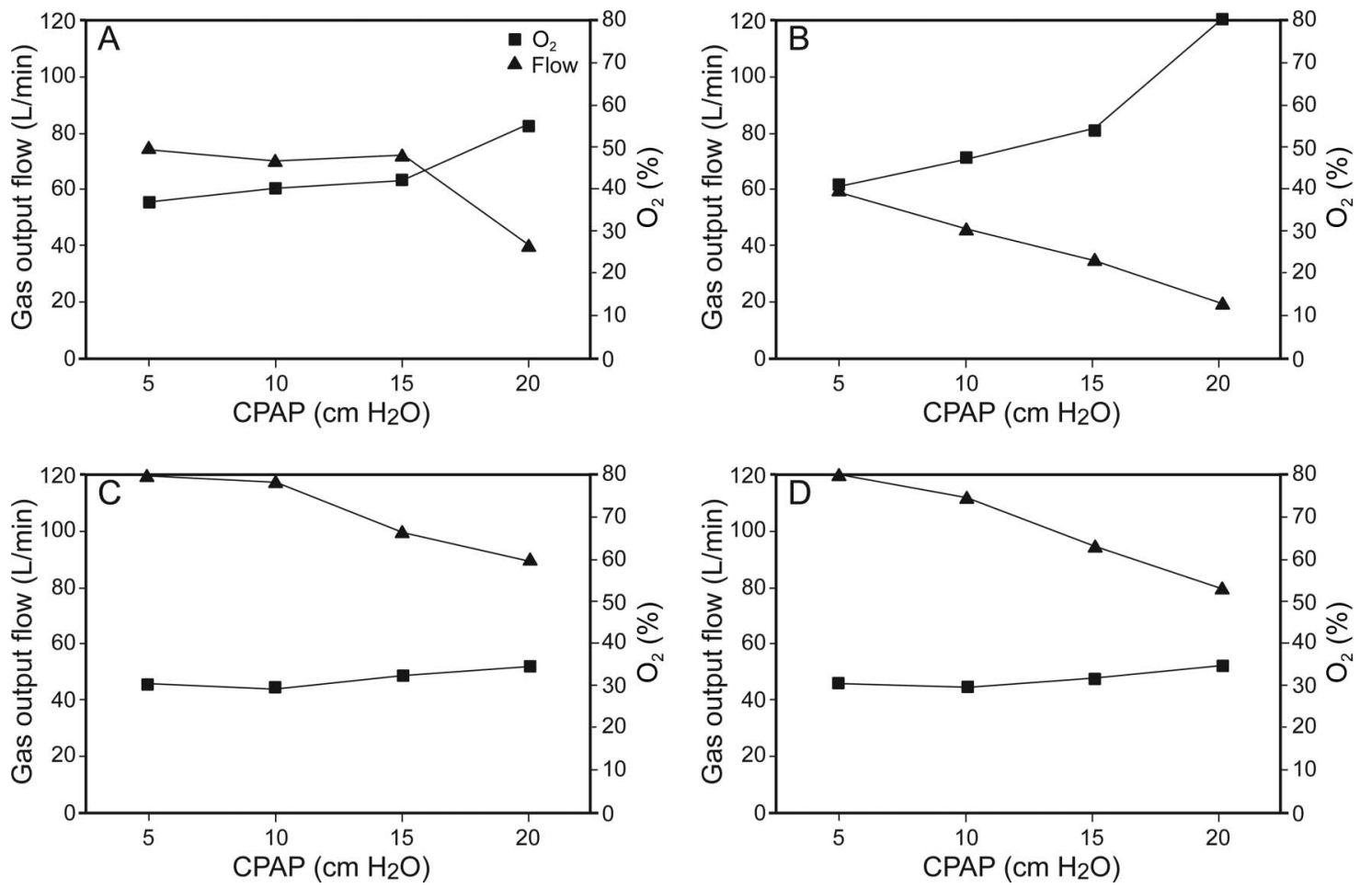

Fig. 5. Ventumask (A), Ventukit (B), EasyVent (C), and EVE Coulisse (D) air-flow outputs at different CPAP levels (5, 10, 15, and 20 cm H2O) and an input flow of $15 \mathrm{~L} / \mathrm{min}$ are shown, as well as $\mathrm{F}_{\mathrm{IO}_{2}}$.

ability to deliver high air flow and $\mathrm{F}_{\mathrm{IO}_{2}}$ and to minimize pressure excursion. (2) The Boussignac CPAP system delivered lower total air flows and higher $\mathrm{F}_{\mathrm{IO}_{2}}$ than air-entrainment devices, with pressure and $\mathrm{F}_{\mathrm{IO}_{2}}$ not independently adjustable. (3) Of the air-entrainment devices, the EasyVent and EVE Coulisse were both more effective and efficient than Ventumask and Ventukit.

In this study, 5 CPAP devices commercially available for prehospital and emergency department use were evaluated: 3 facial masks and 2 helmets. All of these devices are easily usable during ambulance transport because none require electrical power, but only an oxygen source, making them ideal devices for prehospital emergency settings. Four of these devices use the jet air-entrainment principle to entrain room air, increasing the total air flow delivered to the patient, and adjustable CPAP valves to provide CPAP. The Boussignac CPAP system does not entrain ambient air: the virtual Boussignac valve is designed only to establish a positive pressure.

Over the past decade, the Boussignac CPAP system has been used frequently in emergency settings because it is extremely easy to apply and does not require presettings by the operator other than oxygen flow, making it convenient for use by paramedical personnel on ambulances.22-24 We presume that the success of the Boussignac CPAP system is a result of these characteristics and the fact that it delivers a high $\mathrm{F}_{\mathrm{IO}_{2}}$. However, it does not maintain suf- ficient air flow to prevent entrainment of ambient air by the patient, affecting both the effective positive pressure applied and $\mathrm{F}_{\mathrm{IO}_{2}}$ delivered. The positive pressure generated by the virtual valve reached a maximum of $9 \mathrm{~cm} \mathrm{H}_{2} \mathrm{O}$ when driven by $30 \mathrm{~L} / \mathrm{min}$ oxygen. Because the virtual valve is in open communication with the external environment, the oxygen concentration is lowered by dilution by ambient air inspiration, and a drop in airway pressure at high minute ventilation has been observed. ${ }^{25}$ Moreover, with each breath, depending on the patient's respiratory pattern and strength, a negative pressure will be generated during inspiration, and a reversal of flow through the virtual valve will occur during expiration, thus altering the positive pressure generated by the system and therefore not establishing CPAP.

Of the mask-based devices, the EasyVent demonstrated greater efficiency than the Ventumask at the same CPAP and oxygen settings and generated greater air-flow outputs and lower $\mathrm{F}_{\mathrm{IO}_{2}}$. The EasyVent generated high air-flow output even with a CPAP of $20 \mathrm{~cm} \mathrm{H}_{2} \mathrm{O}$, always remaining $\geq 60 \mathrm{~L} / \mathrm{min}$. Moreover, $6 \mathrm{~L} / \mathrm{min}$ oxygen was sufficient to generate an air-flow output of $60 \mathrm{~L} / \mathrm{min}$ without CPAP but maintained a very low $\mathrm{F}_{\mathrm{IO}_{2}}$. The Ventumask generated good air-flow outputs at a CPAP of $5-15 \mathrm{~cm} \mathrm{H}_{2} \mathrm{O}$, but total air-flow output decreased to $25 \mathrm{~L} / \mathrm{min}$ at a CPAP of $20 \mathrm{~cm} \mathrm{H}{ }_{2} \mathrm{O}$, with a consequent increase in $\mathrm{F}_{\mathrm{IO}_{2}}(50 \%)$. Moreover, $10 \mathrm{~L} / \mathrm{min}$ oxygen was needed to generate a total 

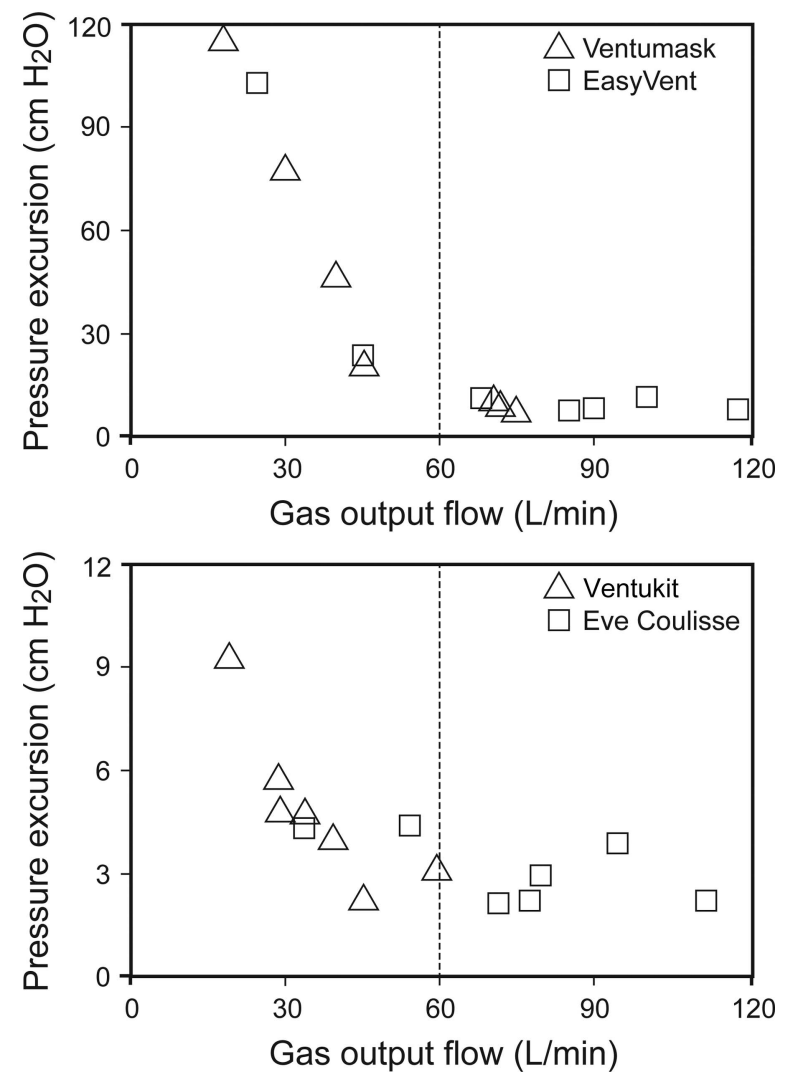

Fig. 6. Relation between pressure excursion and gas output flow in air-entrainment devices. A steep decrease in the first was observed above a threshold of $60 \mathrm{~L} / \mathrm{min}$.

air-flow output of $60 \mathrm{~L} / \mathrm{min}$ at zero CPAP. The differences between these 2 devices in air-flow output may be due to the technical construction of the 2 jet entrainment systems. In fact, with the EasyVent, oxygen flow enters the system in parallel with air flow entrained from the external environment, generating laminar air flow, whereas with the Ventumask, oxygen flow enters at an acute angle to the ambient air flow and entrains less air, possibly due to the generation of turbulence.

Of the helmet devices, the EasyVent and EVE Coulisse were similar in effectiveness, and this result was expected because they both incorporate the same jet entrainment systems applied to 2 different interfaces (mask vs helmet). The Ventukit incorporates the same jet entrainment system as the Ventumask, but the total air-flow output differed between these 2 devices. Inside the helmet at the air-flow output point, the Ventukit includes a plug to reduce the noise generated by the jet entrainment system. This plug certainly reduces the noise inside the helmet, but adds a resistance, measured by the authors as $6 \mathrm{~cm} \mathrm{H}_{2} \mathrm{O}$ per 50 $\mathrm{L} / \mathrm{min}$, significantly reducing the effectiveness of air entrainment. Unfortunately, this reduction in air entrainment limits the use of the Ventukit because the air-flow output was $>60 \mathrm{~L} / \mathrm{min}$ only at a CPAP of $5 \mathrm{~cm} \mathrm{H}_{2} \mathrm{O}$, with an
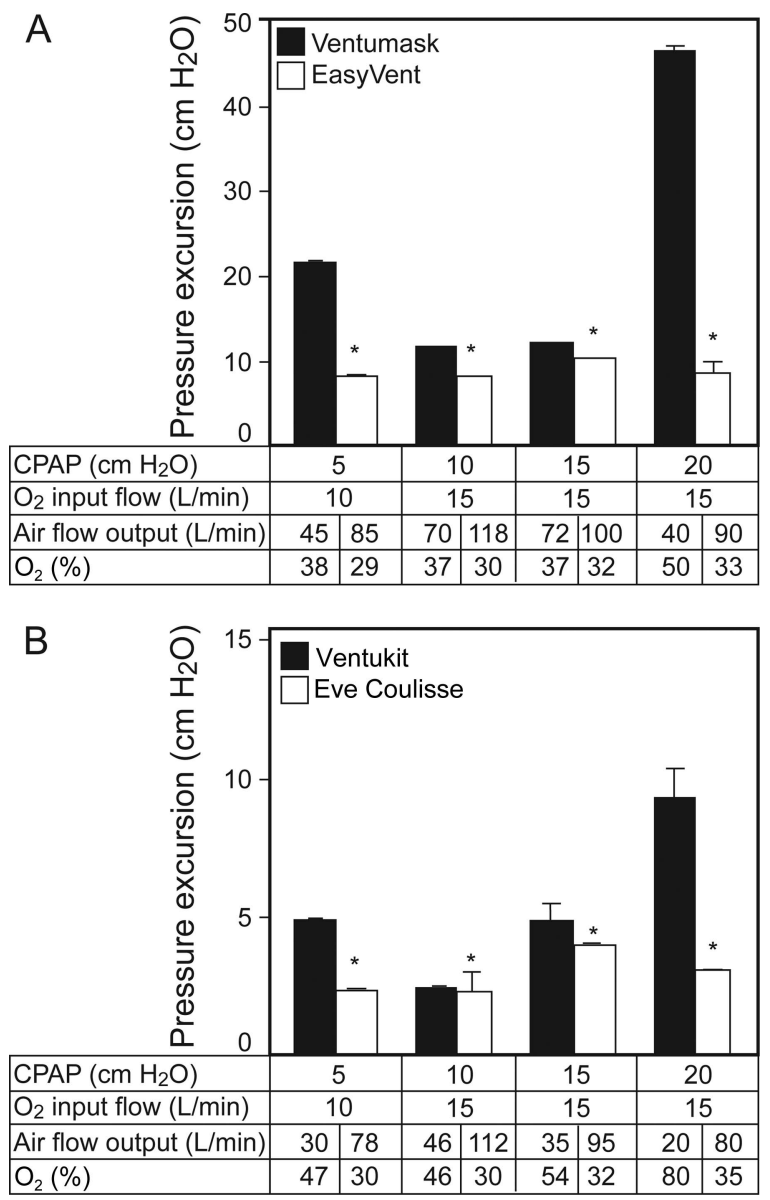

Fig. 7. Pressure excursion (maximum pressure-minimum pressure $=$ excursion pressure) of Ventumask and Easy Vent (panel A) and Ventukit and Eve Coulisse (panel B) during the dynamic bench test. Input flow, pressure, obtained output flow, and $\mathrm{F}_{\mathrm{IO}_{2}}$ are reported. * Significantly lower than the other device compared at the same pressure and input flow $(P<.001)$. The Boussignac CPAP system was not included in this graph because its applied CPAP cannot be adjusted, and it does entrain ambient air.

oxygen consumption of $14 \mathrm{~L} / \mathrm{min}$. An air-flow output $>60$ $\mathrm{L} / \mathrm{min}$ is important in helmets not only to reduce the patient's work of breathing, as with masks, but also to avoid $\mathrm{CO}_{2}$ rebreathing. ${ }^{26,27}$ The EVE Coulisse maintained a total air-flow output well over $60 \mathrm{~L} / \mathrm{min}$ with CPAP set from 5 to $20 \mathrm{~cm} \mathrm{H}_{2} \mathrm{O}$ and consumed from only $8 \mathrm{~L} /$ min oxygen at a CPAP of $5 \mathrm{~cm} \mathrm{H}_{2} \mathrm{O}$ to $13 \mathrm{~L} / \mathrm{min}$ oxygen at a CPAP of 20 $\mathrm{cm} \mathrm{H}_{2} \mathrm{O}$.

Our data also support the clinical relevance of an airflow threshold of $60 \mathrm{~L} / \mathrm{min}$, which is recommended in CPAP guidelines..$^{20,21} \mathrm{We}$ found increased pressure excursion and negative pressure spikes during the inspiratory phase whenever $60 \mathrm{~L} / \mathrm{min}$ was not reached (see Fig. 6). Comparisons between devices systematically showed significantly larger pressure excursion for those devices that did not reach the $60 \mathrm{~L} / \mathrm{min}$ threshold. In helmets, low total air flow also resulted in lower pressures during the inspira- 
Table 2. Oxygen Flow Needed for Each Device at Different CPAP Settings to Reach a Minimum Airflow Output of 6 L/min, Along With Corresponding Estimated Duration of Ambulance Oxygen Flow From a Full 7-L Tank

\begin{tabular}{|c|c|c|c|c|c|c|c|c|}
\hline \multirow{2}{*}{$\begin{array}{l}\text { CPAP Level } \\
\left(\mathrm{cm} \mathrm{H}_{2} \mathrm{O}\right)\end{array}$} & \multicolumn{2}{|c|}{ Ventumask } & \multicolumn{2}{|c|}{ EasyVent } & \multicolumn{2}{|c|}{ Ventukit } & \multicolumn{2}{|c|}{ EVE Coulisse } \\
\hline & Flow (L/min) & Time (min) & Flow $(\mathrm{L} / \mathrm{min})$ & Time $(\min )$ & Flow (L/min) & Time (min) & Flow (L/min) & Time (min) \\
\hline 5 & 11 & 127 & 7 & 200 & 14 & 100 & 8 & 175 \\
\hline 10 & 13 & 107 & 9 & 155 & NA & NA & 10 & 140 \\
\hline 15 & 15 & 93 & 11 & 127 & NA & NA & 11 & 127 \\
\hline 20 & NA & NA & 12 & 116 & NA & NA & 13 & 107 \\
\hline
\end{tabular}

The Boussignac CPAP system was not included in this table because its CPAP level cannot be adjusted a priori, and it does not entrain room air.

$\mathrm{NA}=$ not applicable

tory phase, although pressure remained positive because of the buffering effect of the high internal capacitance of the helmet. Nevertheless, a minimum air-flow output of 60 $\mathrm{L} / \mathrm{min}$ when applying CPAP through helmets is necessary to avoid the risk of $\mathrm{CO}_{2}$ rebreathing due to a low washout flow, in addition to minimizing work of breathing.

The effectiveness of CPAP via mask or helmet at identical air flow and pressure is comparable. ${ }^{28}$ The choice of device depends on other factors, such as operator experience, device availability, expected time of support, and patient's tolerance. Normally, the mask is more readily available and easier to apply, thus making it suitable for ambulance transport. In the emergency department or the wards, however, the helmet allows greater patient comfort and avoids risk of skin lesions. Despite these general considerations, the use of helmets in prehospital settings is feasible, efficient, and safe..$^{5,7}$

The efficiency of CPAP devices is an important topic especially during prehospital use. In fact, in some countries, oxygen availability on ambulances is limited, and transportation times can vary greatly. Furthermore, oxygen sources in ambulances in some countries can generally deliver only up to a maximum of $15 \mathrm{~L} / \mathrm{min}$. Therefore, when higher oxygen flows are needed, as with the Boussignac CPAP system, it is necessary to use 2 tanks simultaneously to achieve a gas delivery of $30 \mathrm{~L} / \mathrm{min}$.

The use of prehospital CPAP has increased considerably in recent years due to the growing evidence regarding the importance of early treatment of pathologies such as acute cardiogenic pulmonary edema ${ }^{5,6}$ and acute hypercapnic respiratory failure. ${ }^{6,9,29}$ However, the most recent studies offer little agreement about the utility of CPAP in improving a patient's outcome. ${ }^{30-32}$ This is, in our opinion, due to the heterogeneity of the approaches used to provide CPAP: many did not specify which CPAP device was used, ${ }^{9,33}$ or they used the Boussignac CPAP system. ${ }^{23,24,34,35}$ In contrast, the studies using air-entrainment CPAP systems concluded that CPAP in prehospital setting is highly effective. ${ }^{8,36,37}$ Due to the variable performance highlighted by this bench study, it is clear that results of clinical trials may be at least partially dependent on the effectiveness of the device used.

Our study has some limitations that need to be addressed. First, the devices were tested only in an in vitro circuit. As a result, we were able to accurately describe and compare the effectiveness and efficiency of each device, but we were not able to reproduce different clinical conditions. Thus, our results cannot be directly extrapolated to the clinical scenario, and larger studies on healthy volunteers and subjects with various respiratory conditions are needed. Second, the devices tested were all CPAP devices for ambulance and emergency settings and are commercially available in Europe. Some new CPAP devices with similar characteristics have recently been developed in the United States. Owing to the heterogeneity of our results obtained with the devices tested in this study, it would be advisable to test with similar methodology the new CPAP devices in the United States but not yet available in Europe.

\section{Conclusions}

In summary, we found considerable differences in performance among the 5 CPAP devices tested. The EasyVent and EVE Coulisse achieved the best overall performance in terms of effectiveness and efficiency; the Ventumask and Ventukit presented more limited air-flow outputs at lower positive pressures; and the Boussignac CPAP system delivered low total air-flow outputs, low positive pressures, and high non-adjustable $\mathrm{F}_{\mathrm{IO}_{2}}$. Clinicians and prehospital caregivers should be aware of specific device performance characteristics to optimize effective application of CPAP in prehospital and emergency settings.

\section{REFERENCES}

1. Antonelli M, Conti G, Rocco M, Bufi M, De Blasi RA, Vivino G, et al. A comparison of noninvasive positive-pressure ventilation and conventional mechanical ventilation in patients with acute respiratory failure. N Engl J Med 1998;339(7):429-435.

2. American Thoracic Society, European Respiratory Society, European Society of Intensive Care Med, Société de Réanimation de 


\section{CPAP in EMERgency Settings}

Langue Française. International Consensus Conferences in Intensive Care Med: noninvasive positive pressure ventilation in acute respiratory failure. Am J Respir Crit Care Med 2001;163(1):283-291.

3. Nourdine K, Combes P, Carton MJ, Beuret P, Cannamela A, Ducreux JC. Does noninvasive ventilation reduce the ICU nosocomial infection risk? A prospective clinical survey. Intensive Care Med 1999;25(6):567-573.

4. Carlucci A, Richard JC, Wysocki M, Lepage E, Brochard L, SRLF Collaborative Group on Mechanical Ventilation. Noninvasive versus conventional mechanical ventilation. An epidemiologic survey. Am J Respir Crit Care Med 2001;163(4):874-880.

5. Garuti G, Bandiera G, Cattaruzza MS, Gelati L, Osborn JF, Toscani $\mathrm{S}$, et al. Out-of-hospital helmet CPAP in acute respiratory failure reduces mortality: a study led by nurses. Monaldi Arch Chest Dis 2010;73(4):145-151.

6. Kosowsky JM, Stephanides SL, Branson RD, Sayre MR. Prehospital use of continuous positive airway pressure (CPAP) for presumed pulmonary edema: a preliminary case series. Prehosp Emerg Care 2001;5(2):190-196.

7. Foti G, Sangalli F, Berra L, Sironi S, Cazzaniga M, Rossi GP, et al. Is helmet CPAP first line pre-hospital treatment of presumed severe acute pulmonary edema? Intensive Care Med 2009;35(4):656-662.

8. Ducros L, Logeart D, Vicaut E, Henry P, Plaisance P, Collet JP, et al. CPAP for acute cardiogenic pulmonary oedema from out-ofhospital to cardiac intensive care unit: a randomised multicentre study. Intensive Care Med 2011;37(9):1501-1509.

9. Kallio T, Kuisma M, Alaspää A, Rosenberg PH. The use of prehospital continuous positive airway pressure treatment in presumed acute severe pulmonary edema. Prehosp Emerg Care 2003;7(2):209-213.

10. Weng CL, Zhao YT, Liu QH, Fu CJ, Sun F, Ma YL, et al. Metaanalysis: noninvasive ventilation in acute cardiogenic pulmonary edema. Ann Int Med 2010;152(9):590-600.

11. Collins SP, Mielniczuk LM, Whittingham HA, Boseley ME, Schramm DR, Storrow AB. The use of noninvasive ventilation in emergency department patients with acute cardiogenic pulmonary edema: a systematic review. Ann Emerg Med 2006;48(3):260-269.

12. Vital FM, Ladeira MT, Atallah AN. Non-invasive positive pressure ventilation (CPAP or bilevel NPPV) for cardiogenic pulmonary oedema. Cochrane Database Syst Rev 2013;5:CD005351.

13. Ferrer M, Esquinas A, Leon M, Gonzalez G, Alarcon A, Torres A. Noninvasive ventilation in severe hypoxemic respiratory failure: a randomized clinical trial. Am J Respir Crit Care Med 2003;168(12): 1438-1444.

14. Meduri GU, Abou-Shala N, Fox RC, Jones CB, Leeper KV, Wunderink RG. Noninvasive face mask mechanical ventilation in patients with acute hypercapnic respiratory failure. Chest 1991;100(2):445-454.

15. Cosentini R, Brambilla AM, Aliberti S, Bignamini A, Nava S, Maffei A, et al. Helmet continuous positive airway pressure vs oxygen therapy to improve oxygenation in community-acquired pneumonia: a randomized, controlled trial. Chest 2010;138(1):114-120.

16. Katz JA, Marks JD. Inspiratory work with and without continuous positive airway pressure in patients with acute respiratory failure. Anesthesiology 1985;63(6):598-607.

17. Bradley TD, Holloway RM, McLaughlin PR, Ross BL, Walters J, Liu PP. Cardiac output response to continuous positive airway pressure in congestive heart failure. Am Rev Respir Dis 1992:145(2 Pt 1):377-382.

18. Kaneko Y, Floras JS, Usui K, Plante J, Tkacova R, Kubo T, et al. Cardiovascular effects of continuous positive airway pressure in patients with heart failure and obstructive sleep apnea. N Engl J Med 2003;348(13): 1233-1241.

19. Fessler HE, Brower RG, Wise RA, Permutt S. Mechanism of reduced LV afterload by systolic and diastolic positive pleural pressure. J Appl Physiol 1988;65(3):1244-1250.
20. British Thoracic Society Standards of Care Committee. Non-invasive ventilation in acute respiratory failure. Thorax 2002;57(3):192-211.

21. Glover GW, Fletcher SJ. Assessing the performance of the Whisperflow continuous positive airway pressure generator: a bench study. Br J Anaesth 2009;102(6):875-881.

22. Templier F, Dolveck F, Baer M, Chauvin M, Fletcher D. Boussignac continuous positive airway pressure system: practical use in a prehospital medical care unit. Eur J Emerg Med 2003;10(2):87-93.

23. Wong DT, Tam AD, Van Zundert TC. The usage of the Boussignac continuous positive airway pressure system in acute respiratory failure. Minerva Anestesiol 2013;79(5):564-570.

24. Spijker EE, de Bont M, Bax M, Sandel M. Practical use, effects and complications of prehospital treatment of acute cardiogenic pulmonary edema using the Boussignac CPAP system. Int J Emerg Med 2013;6(1):8.

25. Sehlin M, Törnell SS, Öhberg F, Johansson G, Winsö O. Pneumatic performance of the Boussignac CPAP system in healthy humans. Respir Care 2011;56(6):818-826.

26. Taccone P, Hess D, Caironi P, Bigatello LM. Continuous positive airway pressure delivered with a "helmet": effects on carbon dioxide rebreathing. Crit Care Med 2004;32(10):2090-2096.

27. Foti G, Patroniti N, Pesenti A. Helmet CPAP in acute respiratory failure. In Vincent JL, editor. Yearbook of intensive care and emergency medicine. Berlin: Springer-Verlag; 2004;411-418.

28. Patroniti N, Foti G, Manfio A, Coppo A, Bellani G, Pesenti A. Head helmet versus face mask for non-invasive continuous positive airway pressure: a physiological study. Intensive Care Med 2003;29(10):16801687.

29. L'HerE, Moriconi M, Texier F, Bouquin V, Kaba L, Renault A, et al. Non-invasive continuous positive airway pressure in acute hypoxaemic respiratory failure-experience of an emergency department. Eur J Emerg Med 1998;5(3):313-318.

30. Simpson PM, Bendall JC. Prehospital non-invasive ventilation for acute cardiogenic pulmonary oedema: an evidence-based review. Emerg Med J 2011;28(7):609-612.

31. Williams B, Boyle M, Robertson N, Giddings C. When pressure is positive: a literature review of the prehospital use of continuous positive airway pressure. Prehosp Disaster Med 2013;28(1):52-60.

32. Williams TA, Finn J, Perkins GD, Jacobs IG. Prehospital continuous positive airway pressure for acute respiratory failure: a systematic review and meta-analysis. Prehosp Emerg Care 2013;17(2):261-273.

33. Cheskes S, Turner L, Thomson S, Aljerian N. The impact of prehospital continuous positive airway pressure on the rate of intubation and mortality from acute out-of-hospital respiratory emergencies. Prehosp Emerg Care 2013;17(4):435-441.

34. Aguilar SA, Lee J, Dunford JV, Castillo E, Lam B, Choy J, et al. Assessment of the addition of prehospital continuous positive airway pressure (CPAP) to an urban emergency medical services (EMS) system in persons with severe respiratory distress. J Emerg Med 2013;45(2):210-219.

35. Frontin P, Bounes V, Houzé-Cerfon $\mathrm{CH}$, Charpentier S, HouzéCerfon V, Ducassé JL. Continuous positive airway pressure for cardiogenic pulmonary edema: a randomized study. Am J Emerg Med 2011;29(7):775-781

36. Dib JE, Matin SA, Luckert A. Prehospital use of continuous positive airway pressure for acute severe congestive heart failure. J Emerg Med 2012;42(5):553-558.

37. Bledsoe BE, Anderson E, Hodnick R, Johnson L, Johnson S, Dievendorf E. Low-fractional oxygen concentration continuous positive airway pressure is effective in the prehospital setting. Prehosp Emerg Care 2012;16(2):217-221. 